\title{
1086 Accurate quantification of simultaneous mitral and tricuspid blood flow using 3D velocity-encoded MRI with retrospective valve tracking
}

\author{
Jos JM Westenberg*, Stijntje D Roes, Albert de Roos, Nico MJ Binnendijk, \\ Joost Doornbos, Jeroen J Bax, Johan HC Reiber and Rob J van der Geest
}

Address: Leiden University Medical Center, Leiden, The Netherlands

* Corresponding author

from I th Annual SCMR Scientific Sessions

Los Angeles, CA, USA. I-3 February 2008

Published: 22 October 2008

Journal of Cardiovascular Magnetic Resonance 2008, I0(SuppI I):A2II doi:I0.II86/I532-429X-I0-SI-A2I I

This abstract is available from: http://jcmr-online.com/content/I0/SI/A2II

(c) 2008 Westenberg et al; licensee BioMed Central Ltd.

\section{Introduction}

In valvular disease, surgical decision-making regarding timing and type of intervention is based on the severity of the regurgitation through the particular atria-ventricular valve. Conventional one-directional (1-dir) velocityencoded (VE) MRI is routinely used for flow assessment over the mitral (MV) and tricuspid valve (TV), but this technique has been shown to be inaccurate and correlation between 1-dir VE MRI MV- and TV-flow measurement is weak.

\section{Purpose}

Validation of three-dimensional (3D) 3-dir VE MRI with retrospective valve tracking during offline analysis for simultaneous MV and TV-flow assessment in phantoms and volunteers without valve regurgitation. The MRI technique is also applied to twenty heart failure patients with valve regurgitation.

\section{Methods}

MRI was performed on a $1.5 \mathrm{~T}$ Gyroscan ACS/NT15 (Philips, Best, the Netherlands). A 3D 3-dir VE MRI sequence (3D volume scan with slab thickness $48 \mathrm{~mm}$, acquisition voxel size $2.9 \times 3.8 \times 4.0 \mathrm{~mm}^{3}$, velocity sensitivity $150 \mathrm{~cm} / \mathrm{s}$ in all directions, with 30 phases reconstructed during one average cardiac cycle, with free breathing in vivo) was designed and tested in stationary flow phantoms and in a phantom simulating harmonic left ventricular filling. Echo Planar Imaging (EPI) was used for accelerating the acquisition (EPI factor 5, in vivo scan time $<5 \mathrm{~min}$ ).

In ten volunteers without valvular regurgitation, $\mathrm{MV}$ and TV-flow was assessed with this 3D 3-dir VE MRI sequence. $\mathrm{MV}$ and TV-flow were reformatted offline using the left and right ventricular cine 2- and 4-chamber views (in 30 corresponding phases/cardiac cycle) as orthogonal guides for the respective planning of the valvular planes (Figure 1). Analysis was repeated by two observers to test intraand inter-observer variation. 1-dir VE MRI at MV and TV was performed for comparison. Systolic aortic flow measured with 1-dir VE MRI was used as the standard of reference.

Finally, MV and TV-flow was assessed in twenty patients with ischemic heart failure and MV and/or TV regurgition.

\section{Results}

Validation in phantoms showed less than 5\% error in flow quantification for either 3D VE MRI or 1-dir VE MRI. In volunteers, a significant bias was found for 1-dir VE MRI for both MV (over-estimation $11 \mathrm{ml} /$ cycle) and TV (over-estimation $12 \mathrm{ml} /$ cycle) compared to the aortic flow volume, while 3D VE MRI showed no bias and small confidence intervals. Correlation with aortic flow volume was strong for $3 \mathrm{D}$ VE MRI ( $\mathrm{r}=0.96$ for $\mathrm{MV}, \mathrm{r}=0.88$ for TV) and strong between MV and TV $(\mathrm{r}=0.91)$. Correlation with aortic flow volume was weak for 1 -dir VE MRI ( $r=0.80$ for 


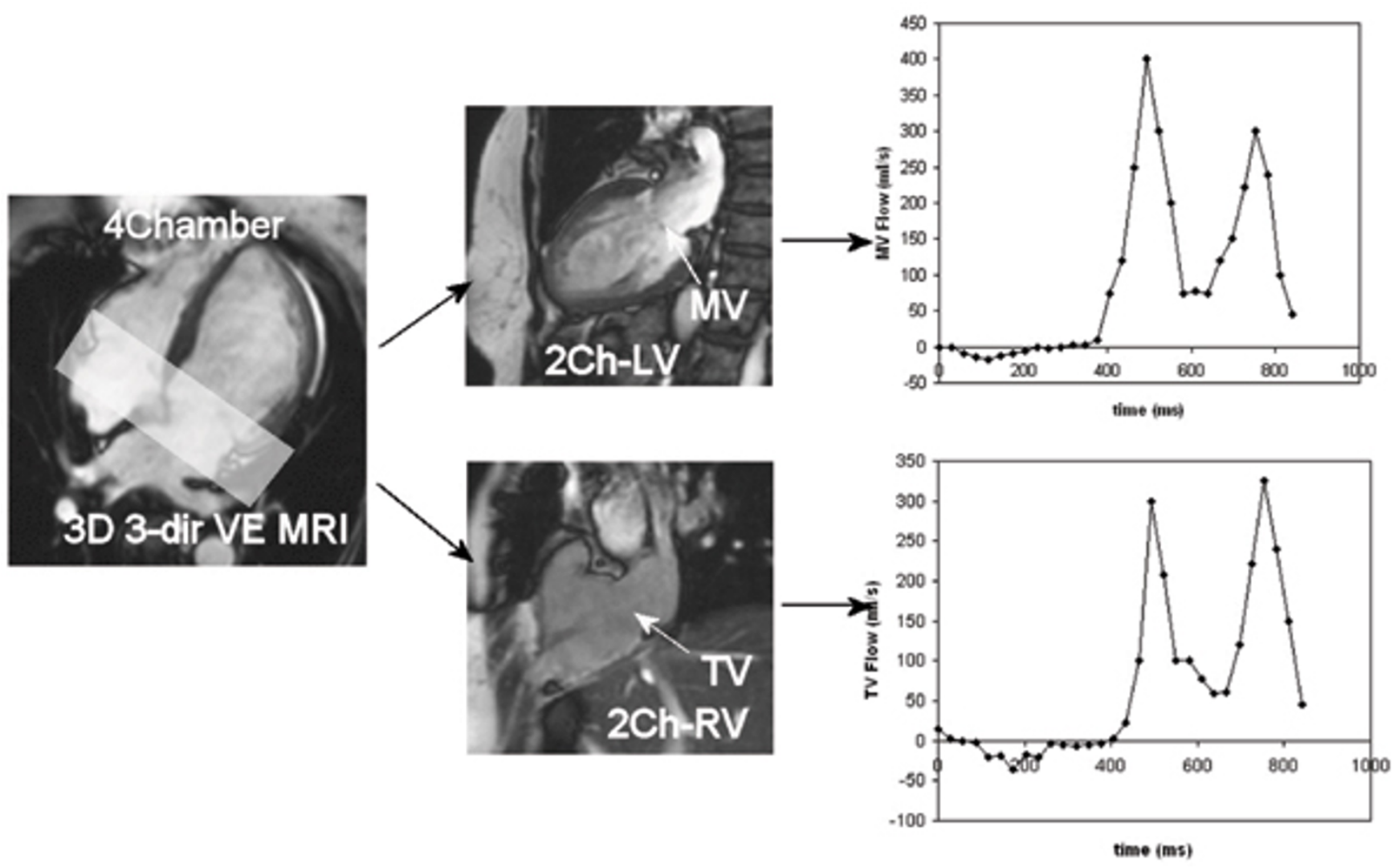

Figure I

Three-dimensional three-directional Velocity-Encoded MRI with retrospective valve tracking during offline analysis is introduced for simultaneous mitral and tricuspid flow assessment. This technique is validated in phantoms and volunteers without valve regurgitation and finally applied to twenty patients with valve regurgitation.

$\mathrm{MV}, \mathrm{r}=0.22$ for TV) and weak between MV and TV $(\mathrm{r}=$ 0.34 ). Coefficient of variation for $3 D$ VE MRI was $<4 \%$ for intra- and $<8 \%$ for inter-observer analysis. In patients (mean regurgitant fraction for $\mathrm{MV}=13 \%$, for $\mathrm{TV}=10 \%$ ), correlation between MV- and TV-flow volume for 3D VE MRI was strong $(r=0.97)$ and there was no significant bias. Figure 2 shows the correlation between the flow volume measured at MV and TV using 3D 3-dir VE MRI in these twenty patients.

Although correlation for MV- and TV-flow with aortic flow was also good, these showed significant bias due to the aortic valve regurgitation that was present in several cases.

\section{Conclusion}

3D VE MRI provides the true trans-valvular MV and TVflow in a single acquisition in less than 5 minutes scan time. Regurgitation through atrio-ventricular valves can be accurately quantified, providing essential information for surgical decision-making. 


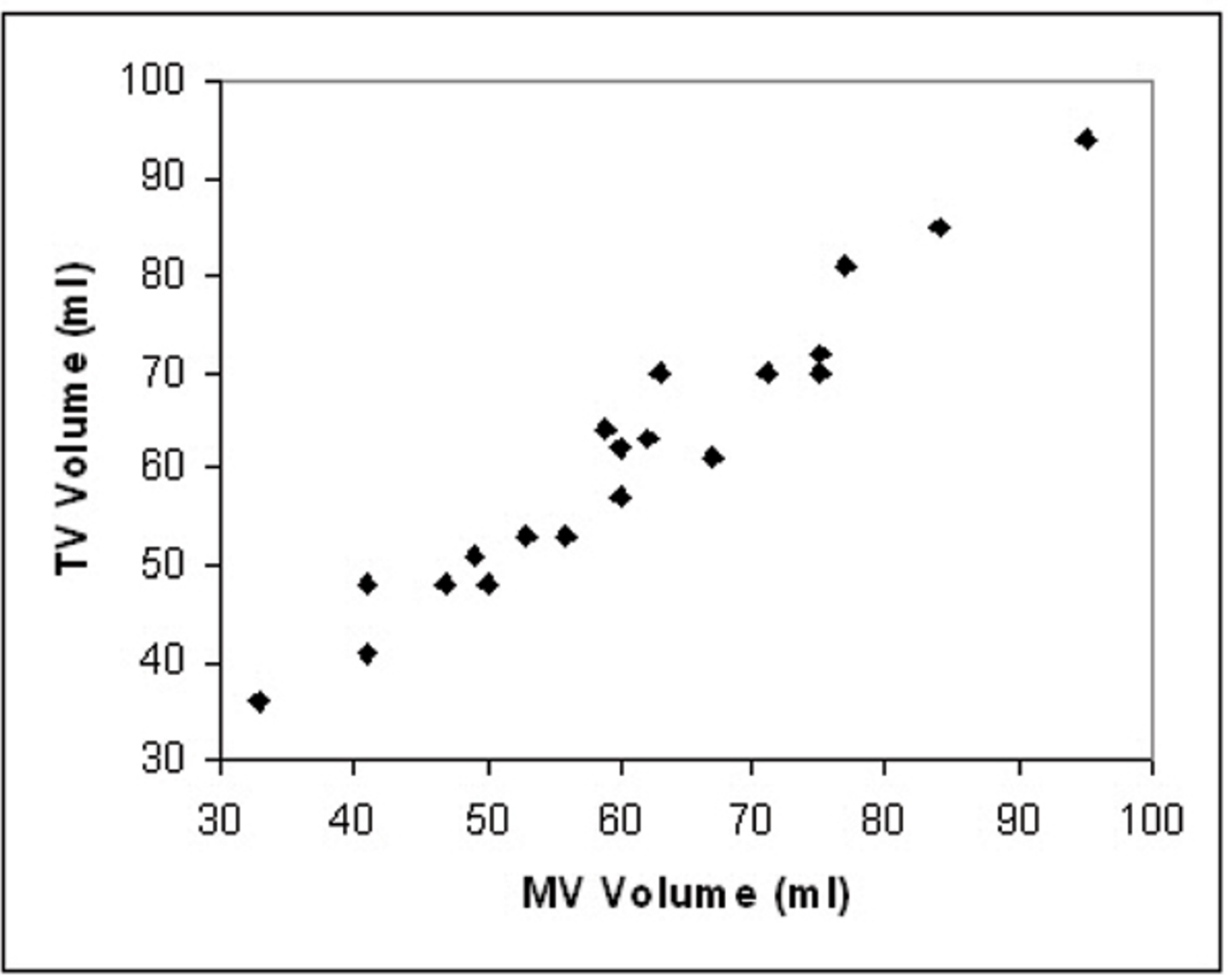

Figure 2

Publish with Bio Med Central and every scientist can read your work free of charge

"BioMed Central will be the most significant development for disseminating the results of biomedical research in our lifetime. "

Sir Paul Nurse, Cancer Research UK

Your research papers will be:

- available free of charge to the entire biomedical community

- peer reviewed and published immediately upon acceptance

- cited in PubMed and archived on PubMed Central

- yours - you keep the copyright
BioMedcentral

Page 3 of 3

(page number not for citation purposes) 